University of Windsor

Scholarship at UWindsor

2009

\title{
Factors Affecting Repeat Visitation and Flow-on Tourism as Sources of Event Strategy Sustainability
}

\author{
Marijke Taks \\ University of Windsor \\ Laurence Chalip \\ B. Christine Green \\ Stefan Kesenne
}

Follow this and additional works at: https://scholar.uwindsor.ca/humankineticspub

Part of the Kinesiology Commons

\section{Recommended Citation}

Taks, Marijke; Chalip, Laurence; Green, B. Christine; and Kesenne, Stefan. (2009). Factors Affecting Repeat Visitation and Flow-on Tourism as Sources of Event Strategy Sustainability. Journal of Sport \& Tourism, $14(2-3), 121-142$.

https://scholar.uwindsor.ca/humankineticspub/33

This Article is brought to you for free and open access by the Faculty of Human Kinetics at Scholarship at UWindsor. It has been accepted for inclusion in Human Kinetics Publications by an authorized administrator of Scholarship at UWindsor. For more information, please contact scholarship@uwindsor.ca. 
FACTORS AFFECTING REPEAT VISITATION AND FLOW-ON TOURISM AS SOURCES OF EVENT STRATEGY SUSTAINABIITY

Marijke Taks (1 \& 4), Laurence Chalip (2), B. Christine Green (2), Stefan Kesenne (3 \& 4), \& Scott Martyn (1)

(1) Department of Kinesiology, University of Windsor, Canada

(2) Sport Management Program, University of Texas at Austin, USA

(3) Department of Economics, University of Antwerp, Belgium

(4) Department of Human Kinesiology, Katholieke Universiteit Leuven, Belgium 


\title{
FACTORS AFFECTING REPEAT VISITATION AND FLOW-ON TOURISM AS SOURCES OF EVENT STRATEGY SUSTAINABIITY
}

\begin{abstract}
The sustainability of including medium sized one-time sport events in an event portfolio is examined with reference to the capacity of one such event to stimulate flow-on tourism (i.e., tourism activities beyond the event but around the time of the event), a desire to return to the destination, and positive word-of-mouth. Relationships among four motives (socialising, escape, learning about the destination, and learning about athletics), identification with the event (self and social identity), previous visitation to the host destination, information search, tourism activities, and likelihood of recommending and/or returning to the host destination were examined for four categories of attendees at the Pan American Junior Athletics Championships: primary purpose spectators, casual spectators, athletes, and non-athlete participants. All four categories of attendee engaged in some information search and participated in flow-on tourism, but to a low degree. Information search fostered flow-on tourism. Classic tourism activities (e.g., sightseeing, visiting museums) were motivated by a desire to learn about the destination, and encouraged future visitation and likelihood of recommendation. It is concluded that medium sized one-time sport events can play a sustainable role in event portfolios, but their efficacy requires greater integration of destination experiences with the event. It is suggested that future work should examine the means to cultivate that integration, including creation of more effective alliances between destination marketers and event organizers.
\end{abstract}


Factors Affecting Repeat Visitation and Flow-on Tourism as Sources of

\section{Event Strategy Sustainability}

The issue of sustainability is receiving increasing research attention in the context of both sport development (e.g., Burnett, 2008; Cunningham \& Beneforti, 2005) and sport events (e.g., Chalip, 2006; Misner \& Mason, 2006; Ohmann, Jones \& Wilkes, 2006). Work in those traditions has sought to identify means to enable economic and/or social benefits that justify sport development or that warrant the expenditures required to host events. Although that work has demonstrated useful economic (e.g., O’Brien, 2006; O’Brien \& Gardiner, 2006) and social (e.g., Kellett, Hede, \& Chalip, 2008) benefits when appropriate leveraging strategies are put into place, benefits are less common in the absence of leverage, and may not be sufficient to justify event expenditures (Allmers \& Maennig, 2008; Burbank, Andranovich, \& Heying, 2001; Levine, 2003). The consequent challenge for establishing a sustainable event strategy is to identify the potential means to leverage each event in a manner that will render current and future tourism value (Chalip, 2004).

This paper examines factors affecting repeat visitation and flow-on activities of event visitors at a one-time sport event: the 2005 Pan American Junior Athletics Championships, hosted in Windsor, Ontario (Canada). Sustainability is conceptualized with reference to the current and future tourism value of the event. The analysis builds from Ritchie, Mosedale, and King's (2002) insight that the types of consumers who are attracted to particular sport events, and their travel behaviour, are critical to the successful use of sport events for tourism purposes. As they point out, by "profiling sport tourism segments based on sport behaviour and motivations, a more accurate picture of tourism leveraging opportunities can be viewed" (p. 42). The current paper examines the tourism information search and tourism activities of different types of event attendees, and considers how these can affect future inbound travel. 


\section{Literature Review}

Types of events and types of visitors. The usefulness of sport events for sustainable tourism does not depend only on the attractiveness of the host destination, but also on the type of sport event. For instance, some events are hosted annually at the same destination (e.g., tennis at Wimbledon), while others move from destination to destination (e.g., the Olympic Games). Each type of event plays a different role in branding the host destination, although the effect of events of this type on repeat visitation and word-of-mouth recommendations is unclear (Jago, Chalip, Brown, Mules, \& Ali, 2003). It is reasonable to expect, however, that recurring events are more likely to attract repeat visitation than are onetime events because some event attendees will return to an event year after year (Green, 2001). Thus, the role that one-time events play in generating flow-on activities (i.e., tourism around the time of the event), repeat visitation, or positive word-of-mouth is a pivotal consideration when evaluating the value of one-time events in a destination's events portfolio.

Moreover, different types of events generate different visitor compositions, affecting the tourism industry and repeat visitation in diverse ways. Mega-events (e.g., the Olympic Games, World Cup Soccer) are classified as "spectator events" because they attract proportionally more spectators than participants (Gratton \& Taylor, 2000). They receive significant media attention and are mainly international in scope. Consequently, their potential to have a long term effect on tourism is expected to be stronger than "medium" sized sporting events. Although medium sized events can also be international in scope, they are classified by Gratton and Taylor as "spectator/competitor" sport events. Medium sized events tend to attract a more balanced number of competitors and spectators, or participants may outnumber spectators. Medium sized sport events receive less media attention and draw 
smaller crowds than do mega-events. Their long-term impact on tourism is therefore also expected to be less than that of mega-events (although that long-term difference has not yet been demonstrated empirically). Visitor composition at this type of event is varied, and both non-local spectators and participants need to be taken into account when studying the tourism effects.

Unlike mega-events which tend to attract travellers whose main purpose is to attend the event, medium-sized events also draw heavily on tourists who discover the event while at the destination. Robinson and Gammon (2004) distinguish these two tourist behaviours as "sport tourism" and "tourism sport", respectively. "Sport tourists" or "primary spectators" are visitors whose primary purpose for visiting the destination is to attend the event, while "tourism sport" or "casual spectators" are visitors at the host destination for another reason, but who choose to attend the event. Because primary spectators are primarily interested in the event, it might be expected that they would be less interested in tourism activities than would casual spectators. Yet, interest in a sport event does not preclude interest in more traditional tourism activities. While the initial travel impetus may vary, members of either group may desire to partake in both event-related activities and traditional tourism activities during their stay (Ritchie et al., 2002).

Participants, whether athletes, coaches, administrators, or officials, are at the host destination for the primary purpose of attending the event either to compete or to fulfill work expectations. A positive experience of the event would be expected to instil a desire to attend the event again. Yet one-time events move from host city to host city. It is the experience of the destination itself that is most likely to result in flow-on tourism around the time of the event or repeat visitation and positive word-of-mouth. Since participants often have free time while at an event, this is the likely point of leverage for destination marketers seeking sustainability through event strategies. For this to work, event organizers and tourism 
marketers should blend the event experience with the destination, since tourist experiences affect future visitation. Profiling visitor segments assists event organizers and tourism marketers in bundling event experiences with the destination, thereby leveraging potential tourism opportunities (Chalip \& McGuirty, 2004).

The Pan American Junior Athletics Championships (PanAM JACs) are an example of a one-time, medium-sized sporting event. This event is organized bi-annually in various Pan American countries under the auspices of the International Association of Athletics Federations (IAAF) and the Pan-American Athletics Commission (PAC). The 2005 event was hosted in Windsor, from July 28-31, by the University of Windsor (Ontario), in partnership with the local track and field club, the community, corporate sponsors, and regional partners. Thirty-five countries were represented at the Championships. Since it was a "junior" championship, the athletes were under 19 years of age. Consequently, the athletes travelled with their team and were accompanied by coaches and team officials. In some cases, family members and/or friends may also have accompanied the athletes on their journey. This type of event attracts a relatively large portion of out of town participants compared to out of town spectators. If the local economy wants to benefit from the event through increased tourism activities, the activities and practices of all out-of-town event visitors are important. Since non-local participants are an important share of the non-localvisitors, participants need to be included in the analysis. However, participants are represented by two distinct groups: the athletes are adolescents (under 19 years of age), but the non-athletes (coaches, officials and others) are adults. It is reasonable to expect that their choice of flow-on activities and their information search will be different, due at least in part to their age difference (Oppermann, 1995; Zalatan, 1996). Thus, two groups of participants need to be considered: athletes and non-athlete participants. In the spectator group, two groups of non-local 
spectators are distinguished: out of town primary spectators and out of town casual spectators.

Information search. Fodness and Murray (1999) review work showing that information search plays a vital role in tourism choices and behavior. Information fosters participation in activities in which visitors would not otherwise engage because they would lack the knowledge that the activities are available. Fodness and Murray point out that information search can take different forms, as there are an array of different information sources and an array of different search strategies in which the potential tourist can engage. The effects of events on information search and consequent tourism behaviours are not well documented, although Ritchie and Smith (1991) show that awareness and interest in a destination rise when the destination hosts a mega-event. Woodside, Spurr, March, and Clark (2002) found that the presence of a mega-event nearly doubles information search by future attendees who have visited the destination previously. Thus, the work suggests that plans to attend an event should stimulate some information search about the host destination (even among those who have previously visited the destination), and information search should increase the amount of flow-on tourism in which event attendees engage.

Information search and tourism activities. It is reasonable to expect that event attendees will search particularly for information about activities in which they presumably are interested (Fodness \& Murray, 1999). Further, their preference for flow-on tourism activities will be many and varied (Chalip \& McGuirty, 2004). Consequently, there is no reason to expect that one set of activities should be more preferred in aggregate than another. The normal procedure for marketing a destination is to inventory the destination's attractions, including available activities, and then to promote them (Fyall \& Garrod, 2005). This is so well established that tourists planning to visit can normally find substantial information about the attractions at a destination prior to their arrival. 
Economists typically cluster tourist activities into categories based on the economic sector in which those activities take place (Hodur \& Liestritz, 2006; Lee, 2006). These typically include nightlife, gaming, dining, and shopping. Natural attractions, such as parks, can also be important (Chalip \& McGuirty, 2004). Thus, these categories of information search and activity are examined here.

Information search and repeat visitation. There are differences between a first time tourist to an area and a repeat tourist regarding their information search (Fodness \& Murray, 1999; Woodside et al., 2002). Relative to repeat visitors, first time tourists typically use more external information sources to become familiar with their destination, accommodation, and activities. Repeat visitors can rely more on their previous experience of the destination. When external information is needed, repeat travellers' information search is greatly affected by their prior trip experience (Chen \& Gursoy, 2000).

Robinson and Gammon (2004) suggest that repeat tourists are different from first time tourists with regard to their motivations. They state that there is a difference between wanting to escape from an environment (first time tourists) and wanting to escape to an environment (repeat tourists). Repeat tourists keep coming back for a reason - a reason linked to the destination itself.

Information search, leisure motivation and subcultural identification. Leisure motivation has been used to examine a variety of travel and tourism activities (e.g., Bieger \& Laesser, 2002; Ryan \& Glenden, 1999; Sirakaya, Uysel, \& Yoshioka, 2003). Although numerous specific motives have been identified, the motives tend to cluster into four overarching categories: intellectual motives, social motives, escape motives, and mastery motives (Beard \& Ragheb, 1983). In addition, identification with a sport subculture can have significant effects on consumption choices and preferences, and thus on tourism activities. People with a high level of identification with a particular sport prefer products and activities 
that display the subculture (Schouten \& McAlexander, 1995) or represent the values of the subculture (Chalip \& McGuirty, 2004). Flow-on tourism activities may therefore be inspired by subcultural identification. Pan and Ryan (2007) suggest that, in a travel context these motives and identity can be considered "push" factors, while the destination's attributes are "pull" factors that "represent opportunities by which the intrinsic motives can be met" (p. 290). Information search, can serve as a link between the two. Thus, a tourist's motives and subcultural identification with the event can be expected to guide him or her to search for information about activities at the destination that would be consistent with those motives and identity.

This study examines the relationship between leisure motives and information search. Four leisure motives taken on Beard and Ragheb's (1983) dimensions of leisure motivation were examined in this study. Two forms of intellectual motivation were relevant in the context of travel to a sport event: learning about the destination and learning about athletics. Social and escape motives were relevant across the sport and travel contexts. Mastery motivation was not considered to be relevant to spectators at the event (Kim \& Chalip, 2004), so was not included in this study.

The conceptual model. Sustainable tourism strategies depend in large measure on their capacity to generate repeat visitation and positive word-of-mouth about the destination (Murphy, Mascardo, \& Benckendorf, 2007; Wang, Severt, \& Rompf, 2005). For events, flow-on tourism (i.e., tourism beyond the event itself) enhances economic impact, and is therefore also a factor in sustainability (Chalip, 2004). These are particularly important in the case of one-time events (cf. Jago et al., 2003). Thus, this study examines key factors leading to successful sustainable outcomes from a one-time sport event. Information search is expected to lead to more participation in tourist activities at the destination. Activities can enhance (or detract from) tourists' experience of the destination, leading to more (or less) 
flow-on tourism, and to affect subsequent word-of-mouth recommendations about the destination. In addition, information search behaviour is expected to be influenced by motives, purpose of the trip and prior experience of the destination. The conceptual model summarizes the relationships suggested by the literature review (see Figure 1).

\title{
$<$ FIGURE 1 here >
}

\author{
Method
}

\section{Sample}

Of the 2829 questionnaires that were distributed to the spectators and participants (athletes, coaches, officials, others) at the event, 1564 were returned, yielding a response rate of $55.3 \%$. Local event attendees, defined as those living in the Windsor/Essex County region, were not considered tourists, and were consequently excluded from further analysis. For purposes of this study, only the responses of non-local event attendees were analysed $(N=458)$. Forty-three surveys were incomplete, resulting in 415 useable questionnaires.

\section{Questionnaire}

Two distinct questionnaires were developed: one for spectators and one for participants. Both questionnaires were available in English and Spanish. During the opening night and subsequent three full days of the event, spectators were approached by surveyors at the front gate and in the stands, and asked to participate in the study. Spectators were asked to complete the survey, and were provided with a pencil and an envelope. Accompanying each survey was a letter explaining the study, including the respondent's rights and the approximate length of time (10 minutes) it would take to complete the survey. They were instructed to return the completed survey in the envelope to the research booth located at the track and field venue. In exchange, they were given a Frisbee emblazed with a Pan American Junior Athletics Championships logo. Participants (athletes, coaches, and officials) received the questionnaire in their welcome package. They were asked to return the questionnaire to the research booth and were invited to participate in a draw for a prize.

Both versions of the questionnaire enquired about: (a) place of residence (in order to distinguish the locals from the non-locals); (b) leisure motivation; (c) tourism information search; (d) 
tourism activities; and, (e) intention to revisit and to recommend the destination. In addition, the spectator survey asked the primary reason for being at the host destination (to distinguish between primary and casual spectators). The participant survey asked about the role of the respondents (athlete, coach, official, administrator, journalist, other), in order to distinguish between athletes and non-athletes. Measures are described below.

\section{Visitor Segments}

Four visitor segments are distinguished: "primary spectators," whose primary reason for being at the destination was to watch the event $(n=195$; age $M=45, S D=15.33$ ); "casual spectators," who were at the destination for a different reason, but came to watch the event $(n=37$; age $M=41, S D=13.61)$; athletes $(n=109$; age $M=18.19, S D=1.00)$, all younger than 19 years of age since it was a junior event; non-athlete participants (coaches, officials, other support staff; $n=74$; age $M=47, S D=11.6$ ).

\section{First Time versus Repeat Visitor}

Spectators and participants were asked whether they had visited Windsor or Essex County previously. If the answer was "no", the respondent was a first time visitor (code $=0$ ); if the answer was "yes" the respondent was a repeat visitor $(\operatorname{code}=1)$.

\section{Leisure Motivation}

Leisure motivation was measured by adapting items from Beard and Ragheb's (1983) Leisure Motivation Scale. The scale measures four dimensions of leisure motivation: (1) social, (2) escape, (3) learning, and (4) mastery. Mastery motivation was only collected from participants, as it seems unlikely that spectators develop mastery by merely watching the event (Kim \& Chalip, 2004). Because only one visitor type responded to items measuring mastery motivation, that subscale was not included in this study. Because of the dual (sport and tourism) nature of the event experience, two types of learning motives were assessed: learning about the destination and learning about athletics. Each dimension was measured using three items (cf. Snelgrove et al., 2008). Items were measured on a 6-point Likert scale ranging from strongly disagree (1) to strongly agree (6). Subscale item scores were averaged 
to form an aggregate measure of the intended motive. Beard and Ragheb (1983) report subscale reliability ranging from .89 for escape to .91 for social motivation. In this study, the four alphas were: .79 (escape), .86 (social), .77 (learning about athletics), and .94 (learning about the destination)

\section{Identification with the Subculture.}

Two aspects of respondents' identification with the subculture of athletics were measured: self identity and social identity. Shamir's (1992) scales of self and social identity were modified to reflect the athletics context (cf. Snelgrove et al., 2008). Three items measured self identity, and three measured social identity. All items were rated on a 6-point Likert scale ranging from strongly disagree (1) to strongly agree (6). The six item scores were averaged to form an aggregate measure of the construct. Shamir reported that both scales are internally consistent, with alphas of .87 for self-identity and .89 for social identity. The two subscales are highly correlated (in this study: $r=.84, p<.001$ ), which recommends their aggregation into a single measure. The alpha for the combined scale in this study was .82 .

\section{Tourism Activities}

The respondents were asked to check the number of times $(0=$ not at all; $1=1$ time; 2 $=2$ times; $3=3$ times; $\geq 4=4$ or more times) they expected to participate in each of ten activities during their stay: dining out, nightlife, shopping, visiting museums and/or galleries, attending performing arts, visiting parks and gardens, doing other recreational activities (e.g., golf), taking in sightseeing tours, visiting historical sites, participating in gaming activities (e.g., going to the casino). Based on smallest space analyses (see results section), the tourism activities were grouped into the following five categories: (a) dining, (b) shopping, (c) parks and gardens, (d) gaming and nightlife, and (e) classic tourism activities (including museums and/or galleries, performing arts, recreational activities, sightseeing tours, and visiting 
historical sites). Tourism activity measures were established based on cluster intensity, which was measured as the number of times an activity was undertaken. The cluster intensity measures for the five activity groupings were skewed, so the variables were log normalized.

\section{Information Search}

In addition to the types of activities undertaken, respondents were asked if they had sought information about each activity prior to coming to the destination. Responses were coded either "yes" = 1 or "no" $=0$. Information search was coded for each of the five activity groupings: dining, shopping, nightlife and gaming, parks and gardens, and classic tourism activities.

\section{Future Visitation}

Future visitation was measured in two different ways: (a) likelihood of returning to the destination in the future; and, (b) likelihood of recommending the destination to friends and family. Respondents were asked to indicate the likelihood on a scale from 1 (= not at all likely) to 6 (= definitely).

\section{Data Analysis}

Smallest space analysis was used to group the tourism activities. Smallest space analysis (Bailey, 1974; Guttman, 1968) determines which activities tend to cluster together and therefore indicates which types of tourism activities can be aggregated. The number of times each respondent engaged in each cluster of activities is then used here for further analysis.

Frequencies and chi-squares (for categorical variables), and mean scores and analysis of variance (for continuous variables) were used to describe the activity patterns and information search by event attendee type, as well as those variables' interrelationships. Correlations were calculated to examine the relationships among the five tourism activities and among information searches for each. 
The final model was analyzed using a three step process. First, backward stepwise logistic regressions were executed to determine which variables affect specific information search for each of the five activities. The independent variables included in the model were the four motivation variables, the two social identity variables, previous visitation (first or repeat visitor), and the type of visitor (three dummy variables were created for primary visitor, athletes and non-athlete participants; casual visitors served as reference group).

Second, hierarchical regressions were used to identify the variables that predict the five tourism activities (the log normalized activity variables were the dependent variables). In the first block, specific information search was entered; in the second block, the four motivation variables, the two social identity variables, type of visitor (the three dummy variables) and previous visitation were entered.

Third, the final model was tested with hierarchical regressions. The dependent variables were "return to the destination" and "recommend the destination". Block 1 contained the five groups of tourism activities; block 2 contained the five specific information searches; and block 3 contained the four motivation variables, the two social identity variables, type of visitor, and previous visitation.

\section{Results}

\section{The Structure of Tourism Activities by Event Attendees}

To determine the structure of tourism activities, a smallest space analysis of all ten tourism activities was performed for all visitor types (in aggregate). The analysis was then repeated for each visitor type. All analyses were fit two dimensionally, and were compared visually. Dining was so distant from the other activities, that it compromised the analyses capacity to differentiate the other tourism activities. Consequently, dining was treated as a separate category, and the analysis was repeated without it. The nine remaining activities were analyzed for the aggregate sample and for each visitor segment. Results were nearly identical 
for all groups, yielding good fit in two dimensions (stress $<.01$ ): touristic-mundane (dimension 1, horizontal axis), and high-low arousal (dimension 2, vertical axis). The resulting aggregate model is shown in Figure 2. As examination of Figure 2 shows, five activities (visiting museums, historical sites, and art galleries, along with sightseeing, and recreation) are clustered together. These are classic (or common) tourism activities.

Shopping sits alone, and is at the relatively mundane (or everyday) end of the first dimension. Gaming and nightlife are jointly at the high arousal end of the second dimension; whereas going to parks and gardens is at the low arousal end of that dimension. Given these findings, five activity clusters are identified: shopping, parks, nightlife and gaming, classic tourism activities, and dining. These five activity clusters are used in all further analyses.

\section{$<$ FIGURE 2 here >}

\section{Previous Visitation}

Little more than half $(51 \%)$ of the total sample reported being a first time visitor to the destination. However, the majority of the participants were first time visitors: $88 \%$ of athletes, and $55 \%$ of the non-athlete participants. In contrast, the majority of the spectators were repeat visitors: $83 \%$ of the casual spectators and $66 \%$ of the primary spectators $\left(\chi^{2}[3, N\right.$ $=415]=99.99, \mathrm{p}<.001)$.

\section{Tourism Activities}

Table 1 compares the frequency of participation in each activity category by each group. As inspection of the table shows, dining is the only activity with a significant difference between visitor segments; both spectator groups (primary and casual attendees), dine out more often that the participant groups (athletes and non-athlete participants). This is not remarkable, since the participants were provided with room and board. As such, participants consumed most meals in the athletes' village. The groups did not differ 
significantly in their shopping, classic tourism activities, use of parks and gardens, or consumption of nightlife and gaming.

$<$ TABLE 1 here >

\section{Information Search}

Table 2 reports the percentage of each visitor type who searched for information about each activity. Aggregate search percentages are also reported. As inspection of the table shows, pre-event search behaviours were quite infrequent, with fewer than one in five attendees reporting having searched for information about any one tourism activity. Overall, the activities most searched for prior to coming to the destination were dining (17.3\%) and classic tourism activities $(16.1 \%)$. The athletes sought significantly more information about shopping activities prior to attending the event when compared to any other group.

$<$ TABLE 2 here >

\section{Future Visitation}

Table 3 shows respondents' rated likelihood (on the six-point scale) for recommending or returning to Windsor/Essex County. As inspection of the table shows, event attendees reported (on average) at least some likelihood of returning to Windsor/Essex County. Casual spectators were most likely to expect to return, and primary purpose spectators were more likely than either group of participants to expect to return. Athletes and non-athlete participants reported being less likely to return than either spectator type.

$<$ TABLE 3 here >

Event attendees reported being likely to recommend the destination to others. There were few differences among the groups on this variable. Casual spectators and non-athlete participants differed slightly, with casual spectators being more likely than non-athlete participants to recommend the destination to others. There was a moderate correlation 
between the likelihood of returning to Windsor/Essex County and the likelihood of recommending it to others $(r=.57 ; p<.001)$.

\section{Relationship between Information Search and Tourism Activities}

Table 4 reports the correlations among tourism activities and among the variables measuring information search about the tourism activities. All correlations are positive and significant. Classic tourism and parks show the highest correlations for activities $(r=.51, p<$ $.01)$ and for information search $(r=.72, p<.01)$.

\section{$<$ TABLE 4 here >}

Table 5 compares the activity levels of attendees who did and did not search for information about an activity. As the table shows, specific information search is highly related to participation in the same activity. Those who sought information about an activity were also more likely to engage in that activity. Moreover, a crossover effect is apparent. Whenever people search for information, they tend to be more active in their overall tourism behaviour. For example, people who search for information on classic tourism activities, do more classic tourism activities than those who do not search, but they also visit more parks and gardens than do non-searchers. This crossover effect is significant for nearly all information search and tourism activities.

$<$ TABLE 5 here >

\section{Variables Affecting Specific Information Search}

Each of the individual information search variables was regressed on participants' motives, subcultural identity, purpose for attending, and previous visitation. Table 6 presents the outcomes of the backward stepwise logistic regression analyses. The motive "learning about the destination" positively predicted information search in all five regressions. Previous visitation negatively affected information search for three of the five search categories: dining, shopping, and to a lesser extent classic tourism activities. As expected, 
repeat visitors searched less when compared to first time visitors. Finally, the more attendees were motivated by "learning about athletics", the less likely they were to seek information about nightlife and gaming. Spectators and participants who attended the event to learn more about athletics were not interested in information on nightlife and gaming.

$<$ TABLE 6 here >

\section{Variables Affecting Specific Tourism Activities}

Table 7 provides a summary of the variables predicting participation in specific tourism activities. The results are based on hierarchical regression analyses. In each case, specific search on the activity is entered in the first block. In the second block, all other variables are entered (i.e., motives, type of visitor, and repeat visitation). Specific information search positively predicts participation in the respective activity for all activities. With the exception of nightlife and gaming, participation in activities is negatively affected by previous visitation. Respondents with prior experience at the destination were less likely to go out for dinner, visit parks, go shopping, or participate in classic tourism activities. First time visitors were more likely to participate in all these activities. Athletes stand out by participating significantly less than casual spectators in dining, classic tourism, and visiting parks. Status as a non-athlete participant also resulted in less dining out than either spectator group. Since room and board was provided for the participants (athletes and non-athletes) this is not surprising. Motivation to learn about the destination predicted participation in classic tourism activities. Lastly, participation in nightlife and gaming was only related to seeking information about nightlife and gaming.

\section{$<$ TABLE 7 here $>$}

\section{Predicting Future Tourism Impact and Flow-on}

Two models were tested to examine key tourism outcomes: repeat visitation and recommendations. The first model examines which factors affect event attendees' likelihood 
to revisit; the second model identifies which variables affect the likelihood that visitors will recommend the destination to family and friends. Hierarchical regression analyses were performed. All five tourism activities were entered in the first block, followed by the five specific information searches in block 2. Previous visitation, visitor type, motives, and identity were entered in the third and final block. Specific information seeking (Block 2) did not predict either repeat visitation $\left[R^{2}=.049, \Delta R^{2}=.011, F(5,404)=0.92, p=.467\right]$ or recommendation $\left[R^{2}=.064, \Delta R^{2}=.022, F(5,404)=1.86, p=0.01\right]$. Consequently, both models were modified. Block 2 was removed and new hierarchical regressions were performed, with a final model retained after removing insignificant predictors. The final model is presented in Table 8.

\section{$<$ TABLE 8 here $>$}

Three variables significantly and positively predict both repeat visitation and recommendation: previous visitation, classic tourism activities, and escape motivation. In addition to these variables, the motive, "learning about the destination", plays a significant role in increasing the likelihood that attendees will recommend the destination to others. Park activities, on the other hand, decrease the likelihood that visitors will return or recommend the destination. Thus, parks and garden do not seem to foster future visitation, but classic tourism activities do, as does the motive to escape. In addition, repeat visitors are more likely to return to Windsor/Essex County and to recommend the destination to others. People who want to learn about the destination are also more likely to recommend the host city.

Nine key findings are summarized below and graphically represented in Figure 3.

1. Event attendees who want to learn about the destination seek out information on a wide variety of activities prior to coming to the destination, and participate in significantly more classic tourism activities. 
2. Repeat visitors seek less information on shopping, dining and classic tourism activities than do first time visitors.

3. Repeat visitors also tend to participate less in activities such as shopping, dining, classic tourism activities and parks and gardens.

4. Spectators and participants who attend the event to learn about athletics show no interest in information about nightlife and gaming.

5. Information search on a specific activity leads to more participation in the activity.

6. Athletes are a distinctive visitor group since they participate less in dining or classic tourism activities, and are less likely to visit parks and gardens than other visitor groups.

7. In line with the athletes, non-athlete participants do not go out for dinner as often as spectators.

8. Classic tourism activities and the escape motive generate future visitation, while visits to parks and gardens does not.

9. If people attending the event also want to learn about the destination, they are more likely to recommend the destination to friends and family upon their return home.

$<$ FIGURE 3 here >

\section{Discussion}

From the standpoint of sustainability, the key concerns are the degree to which a medium sized one-time event can generate flow-on tourism, repeat visitation, or positive word-of-mouth. In fact, event attendees did participate in some tourism activities, although spectators were more likely to do so than participants. This is consistent with the view that participants (whether athletes or not) are focused on their event participation, and are therefore less likely to undertake tourism activities. 
At first blush, this may seem to recommend events that attract high numbers of spectators relative to participants - probably mega-events. However, a closer examination of the findings shows that participants, particularly athletes, were most inclined to seek opportunities to shop - an activity likely to enhance the economic impact of the event. Further, participants and spectators who participated in tourism activities were more likely to have obtained information about tourism activities before coming to the event. Further, participation in tourism activities, particularly classic tourism activities, rendered a greater likelihood that event attendees would expect to return to the host destination, and a greater propensity to recommend the destination. Thus, the challenge seems to be to encourage tourism by attendees, which includes getting information about tourism possibilities before they arrive at the event.

The requisite tactics require that tourism marketers and event organizers work more closely together to stimulate interest and information search, and to provide tourism opportunities particularly gauged to the interests of those who will attend the event (cf. Green, 2001). Tourism activities can even be bundled with event registrations or travel arrangements (Chalip \& McGuirty, 2004). Thus, flow-on tourism levels may be low, as in this study, not because event attendees are uninterested, but because tourism was not effectively marketed to those who would attend. Weed (2003) found that tourism organizations and sport organizations do not often work well together. The challenge, then, is to forge more effective alliances between event organizers and destination marketers in order to build on attendees' interest in flow-on tourism.

There are clearly motivational bases for building those appeals. A desire to learn about the destination had a positive impact on all forms of information search, and a consequently indirect effect on participation in all activities. Further, it had a direct and positive effect on participation in classic tourism. This is an interesting finding as it suggests 
that flow-on tourism for event attendees is not merely driven by the pull of icons and attractions (e.g., Pan \& Ryan, 2007), but is driven particularly by the desire to learn about the destination. It has been shown elsewhere that the desire to learn about a host destination also fosters interest in attending an event (Kim \& Chalip, 2004). Thus, event organizers and destination marketers have a potentially shared interest in promoting a desire to learn about the destination. This suggests an effective basis for marketing appeals to future and potential event attendees, particularly those who have not previously visited the destination.

The way the event is organized is also clearly important. In this study, participants spent less time dining out than did spectators, presumably because participants' meals were provided by event organizers. The localization of meals at the athlete village served to discourage time away from the village. Similarly, competition schedules may also have interfered with tourist activity. This is quite common at events, but it is a matter of tradition, rather than necessity. A more creative approach to organizing meals or competition schedules might encourage more involvement with the destination. For example, vouchers that participants could use to eat on some occasions in local eating establishments would encourage them to take some meals away from the village. Similarly, competition schedules providing predictable free time might encourage more tourism. Indeed, some tourist activities could be built into participants' schedules. Again, the challenge is for destination marketers and event organizers to find more creative ways to blend destination experiences into the event experience. The findings here suggest that would enhance participants' overall experience, thereby encouraging both return and recommendation.

Although spectators felt it was likely that they would return to the destination, participants did not. All groups were somewhat likely to recommend the host destination, but they were more likely to do so to the degree that they had participated in some classic tourism activities. Again, it is clear that experience of the destination is pivotal. However, it is not 
the only relevant factor. The degree to which attendees desired to escape from their daily lives also affected the likelihood that they would return or recommend. This suggests a useful tack to take when formulating marketing appeals targeted at those who previously attended an event at the destination. The finding that previous visitation can also encourage return, suggests that escape-oriented appeals might be particularly effective if they are grounded in a sense of nostalgia (cf. Fairley, 2003).

One of the surprising findings of this study was that spending time in parks had a negative effect on likelihood of return and likelihood of recommendation. The reasons for this finding are unclear. It could simply be that the parks at this particular host destination were not sufficiently appealing to encourage future visitation; it could be that parks are not sufficiently distinctive to warrant future visitation; it could be that time in the parks was time taken away from more memorable tourism activities; or a combination of these. Going to parks and gardens was identified as a 'low arousal' activity, in contrast with nightlife and gaming which was on the high arousal end of the spectrum. Although the host destination is well known for gaming opportunities this type of activity did not appeal to participants in this event. Future work should explore the bases for effective and ineffective uses of parks to foster repeat visitation and positive word-of-mouth.

Several other research directions suggest themselves as a consequence of this research. The challenges of forging effective alliances between sport event organizers and host destinations need to be better understood. Factors that facilitate and that hinder such relationships need to be identified, and the means to optimize the outcomes from such alliances need to be determined.

Effective appeals to market the destination to future event visitors and former event visitors need to be explored, and the ways in which those appeals can replicate other tourism marketing communications or should be different for event market segments should be 
examined. In particular, event attendees' interests in learning about the destination need to be better understood, and the means to capitalize on those interests need to be mapped. Refining measures and identifying those factors that motivate search and consequent behaviour, the strength of prediction among variables will also be increased.

There seems to have been a sufficient impact from this medium sized one-time event to suggest that such events can be useful and therefore sustainable inclusions in a destination's events portfolio. The core challenge is to find more effective ways to blend the event attendee's experience of the event with his or her experience of the destination. To date, this has largely been haphazard. Research into the effects of such events on flow-on tourism, repeat visitation, and positive word-of-mouth will help us to better understand the complex relationships between host destinations, events, and the consumers who attend them. 


\section{References}

Allmers, S., \& Maennig, W. (2008). South Africa 2010: economic scopes and limits. In The impact of mega events on developmental goals: The 2010 FIFA World Cup in South Africa (pp. 1-31). Stellenbosch, SA: University of Western Cape/VLIR \& UOS.

Bailey, K.D. (1974). Interpreting smallest space analysis. Sociological Methods and Research, 3, 3-29.

Beard, J.G., \& Ragheb, M.G. (1983). Measuring leisure motivation. Journal of Leisure Research, 15, 219-228.

Bieger, T., \& Laesser, C. (2002). Market segmentation: The case of Switzerland. Journal of Travel Research, 41, 68-76.

Burbank, M.J., Andranovich, G.D., \& Heying, C.H. (2001). Olympic dreams: The impact of mega-events on local politics. Boulder, CO: Rienner Publishers.

Burnett, C. (2008). Accounting for sport development. In V. Girginov (Ed.), Management of sports development (pp. 259-175). London, UK: Elsevier/BH.

Chalip, L. (2004). Beyond impact: A general model for sport event leverage. In B.W. Ritchie \& D. Adair (Eds.), Sport tourism: Interrelationships, impacts and issues (pp. 226-252).

Clevedon, UK: Channel View Publications.

Chalip, L. (2006). Towards social leverage of sport events. Journal of Sport \& Tourism, 11, 109-127.

Chalip, L., \& McGuirty, J. (2004). Bundling sport events with the host destination. Journal of Sport Tourism, 9, 267-282

Chen, J. \& Gursoy, D. (2000). Cross-cultural comparison of the information sources used by first-time and repeat travelers and its marketing implications. International Journal of Hospitality Management, 19(2), 191-203.

Cunningham, J., \& Beneforti, M. (2005). Investigating indicators for measuring the health and social impact of sport and recreation program in Australian indigenous communities. International Review for the Sociology of Sport, 40, 89-98.

Fairley, S. (2003). In search of relived social experience: Group based nostalgia sport tourism. Journal of Sport Management, 17, 284-304.

Fodness, D. \& Murray, B. (1999). A model of tourist information search behaviour. Journal of Travel Research, 37(3), 220-230. 
Fyall, A., \& Garrod, B. (2005). Tourism marketing: A collaborative approach. Clevedon, UK: Channel View Publications,

Gratton, C., \& Taylor, P. (2000). Economics of sport and recreation. London: Spon.

Green, B.C. (2001). Leveraging subculture and identity to promote sport evenst. Sport Management Review, 4, 1-19.

Guttman, L. (1968). A general nonmetric technique for finding the smallest coordinate space for a configuration of points, Psychometrika, 33, 469-506.

Hodur, N.M., \& Leistritz, F.L. (2006). Estimating the economic impact of event tourism: A review of issues and methods. Journal of Convention \& Event Tourism, 8(4), 63-79.

Jago, L., Chalip, L., Brown, G., Mules, T., \& Ali, S. (2003). Building events into destination branding: Insights from experts. Event Management, 8, 3-14

Kellett, P., Hede, A-M, \& Chalip, L. (2008). Social policy for sport events: Leveraging (relationships with) teams from other nations for community benefit. European Sport Management Quarterly, 8, 101-121.

Kim, N-S., \& Chalip, L. (2004). Why travel to the FIFA World Cup? Tourism Management, 25, 695-707.

Lee, M.J. (2006). Analytic reflections on the economic impact assessment of conventions and special events. Journal of Convention \& Event Tourism, 8(3), 71-85.

Levine, M.C. (2003). Tourism-based redevelopment and the fiscal crisis of the city: The case of Montreal. Canadian Journal of Urban Research, 12, 102-123.

Misner, L., \& Mason, D. (2006). Creating community networks: Can sporting events offer meaningful sources of social capital? Managing Leisure, 11, 39-56.

Murphy, L., Mascardo, G., \& Benckendorff, P. (2007). Exploring word-of-mouth influences on travel decisions: Friends and relatives vs. other travellers. Internatinoal Journal of Consumer Studies, 31, 517-527.

O'Brien, D. (2006). Event business leveraging: The Sydney 2000 Olympic Games. Annals of Tourism Research, 33, 240-261.

O’Brien, D., \& Gardiner, S. (2006). Creating sustainable mega events impacts: Networking and relationship development through pre-event training. Sport Management Review, 9, 2547.

Ohmann, S., Jones, I. \& Wilkes, K. (2006). The perceived social impacts of the 2006 Soccer World Cup on Munich Residents. Journal of Sport and Tourism, 11, 129-152.

Oppermann, M. (1995). Travel life cycle. Annals of Tourism Research, 22, 535-552. 
Pan, S., \& Ryan, C. (2007). Mountain areas and visitor usage - Motivations and determinants of satisfaction: The case of Pirongia Forest Park, New Zealand. Journal of Sustainable Tourism, 15, 288-308.

Ritchie, B., Mosedale, L., \& King, J. (2002). Profiling sport tourists: The case of Super 12 Rugby Union in the Australian Capital Territory, Australia. Current Issues in Tourism, 5, 3344.

Ritchie, J.B.R., \& Smith, B. (1991). The impact of a mega-event on host region awareness: A longitudinal study. Journal of Travel Research, 30(1), 3-10.

Robinson, T., \& Gammon, S. (2004). A question of primary and secondary motives:

Revisiting and reapplying the sport tourism framework. Journal of Sport Tourism, 9, 221 233.

Ryan, C., \& Glendon, I. (1999). Application of leisure motivation scale to tourism. Annals of Tourism Research, 25, 169-182.

Schouten, J.W., \& McAlexander, J.H. (1995). Subcultures of consumption: An ethnography of the new bikers. Journal of Consumer Research, 22, 43-61.

Shamir, B. (1992). Some correlates of leisure identity salience: Three exploratory studies. Journal of Leisure Research, 24, 301-323.

Sirakaya, E., Uysal, M., \& Yoshioka, C.F. (2003). Segmenting the Japanese tour market to Turkey. Journal of Travel Research, 41, 293-304.

Wang, Y., Seyert, D., \& Rompf, P. (2005). Examining the nature and dynamics of atdestination recommendations: The local experts' perspective. Journal of Hospitality \& Leisure Marketing, 13, 139-160.

Weed, M. (2003). Why the two won't tango! Explaining the lack of integrated policies for sport and tourism in the UK. Journal of Sport Management, 17, 258-283.

Woodside, A.G., Spurr, R., March, R., \& Clark, H. (2002). The dynamics of traveler destination awareness and search for information associated with hosting the Olympic Games. International Journal of Sports Marketing \& Sponsorship, 4, 127-150.

Zalatan, A. (1996). The determinants of planning time in vacation travel. Tourism Management, 17, 123-131. 
Table 1

Intensity of Tourism Activities by Type of Event Attendee

\begin{tabular}{lccccc} 
Activity & $\begin{array}{c}\text { Primary } \\
\text { spectator }\end{array}$ & $\begin{array}{c}\text { Casual } \\
\text { spectator }\end{array}$ & Athletes & $\begin{array}{c}\text { Participant } \\
\text { non-athletes }\end{array}$ & $F(3,411)$ \\
\hline Dining & $2.59^{\mathrm{a}}$ & $2.31^{\mathrm{a}}$ & $1.31^{\mathrm{b}}$ & $1.45^{\mathrm{b}}$ & $23.674^{*}$ \\
Parks \& gardens & 0.63 & 0.81 & 0.57 & 0.78 & 0.978 \\
Shopping & 0.94 & 1.27 & 1.28 & 1.14 & 2.281 \\
Nightlife \& & & & & & \\
gaming & 1.08 & 1.19 & 0.87 & 1.26 & 1.03 \\
Classic tourism & 0.81 & 1.16 & 0.75 & 0.93 & 0.483 \\
\hline
\end{tabular}

$* p<.001$

${ }^{\text {a }}$ significantly different from athletes and non-athlete participants

${ }^{\mathrm{b}}$ significantly different from primary and casual spectators 
Table 2

Information Search on Tourism Activities by Type of Event Attendee (percentage searching)

\begin{tabular}{lcccccc} 
Information & $\begin{array}{c}\text { Primary } \\
\text { spectator }\end{array}$ & $\begin{array}{c}\text { Casual } \\
\text { spectator }\end{array}$ & Athletes & $\begin{array}{c}\text { Participant } \\
\text { non-athletes }\end{array}$ & $\begin{array}{c}\text { Aggregate } \\
\text { sample }\end{array}$ & $\begin{array}{c}\chi^{2}(d f=3) \\
(N=415)\end{array}$ \\
\hline $\begin{array}{l}\text { Dining } \\
\begin{array}{l}\text { Parks \& } \\
\text { gardens }\end{array}\end{array}$ & 16.9 & 8.1 & 22 & 16.2 & 17.3 & 3.952 \\
$\begin{array}{l}\text { Shopping } \\
\text { Nightlife \& }\end{array}$ & 7.7 & 5.4 & 11.9 & 10.9 & 9.2 & 2.377 \\
gaming & 7.7 & 5.4 & $22^{\mathrm{a}}$ & 9.5 & 11.6 & $16.197^{*}$ \\
Classic tourism & 10.3 & 13.5 & 14.7 & 10.8 & 11.8 & 1.488 \\
\hline
\end{tabular}

$* p<.01$

${ }^{a}$ significantly different from all other groups 
Table 3

Future Visitation by Type of Event Attendee

\begin{tabular}{lllllc} 
Activity & $\begin{array}{c}\text { Primary } \\
\text { spectator }\end{array}$ & $\begin{array}{c}\text { Casual } \\
\text { spectator }\end{array}$ & Athletes & $\begin{array}{c}\text { Participant } \\
\text { non-athletes }\end{array}$ & $F(3,411)$ \\
\hline Return to destination & $4.09^{\text {ab }}$ & $5.36^{\text {bcd }}$ & $2.87^{\text {ac }}$ & $3.53^{\text {a }}$ & $25.222^{* *}$ \\
Recommend destination & 4.35 & $4.43^{\text {d }}$ & 3.92 & $3.72^{\text {a }}$ & $3.87^{*}$ \\
\hline$* p<.01 ; * p<.001$ & & & & \\
\hline a significantly different from casual spectators & & & \\
'b significantly different from athletes & & & & \\
c significantly different from primary spectators & & &
\end{tabular}


Table 4

Correlation Matrices for Tourism Activities and Information Search

\begin{tabular}{|c|c|c|c|c|c|}
\hline & Dining & Shopping & Parks & $\begin{array}{c}\text { Nightlife \& } \\
\text { Gaming }\end{array}$ & $\begin{array}{l}\text { Classic } \\
\text { Tourism }\end{array}$ \\
\hline \multicolumn{6}{|l|}{ Activities } \\
\hline Dining & 1 & $.32^{* \star *}$ & $.24^{\star \star *}$ & $.33^{\star *}$ & $.21^{\star *}$ \\
\hline Shopping & & 1 & $.22^{\star \star}$ & $.31^{* *}$ & $.34^{\star *}$ \\
\hline Parks & & & 1 & $.24^{\star *}$ & $.51^{\star \star}$ \\
\hline Nightlife \& Gaming & & & & 1 & $.32^{\star \star}$ \\
\hline Classic Tourism & & & & & 1 \\
\hline \multicolumn{6}{|l|}{ Information } \\
\hline Dining & 1 & $.41^{\star *}$ & $.34^{\star *}$ & $.46^{\star *}$ & $.40^{\star \star}$ \\
\hline Shopping & & 1 & $.41^{\star *}$ & $.36^{\star *}$ & $.44^{\star *}$ \\
\hline Parks & & & 1 & $.30^{\star *}$ & $.72^{\star \star}$ \\
\hline Nightlife \& Gaming & & & & 1 & $.33^{*}$ \\
\hline Classic Tourism & & & & & 1 \\
\hline
\end{tabular}

${ }^{*} p<.05 ;{ }^{* *} p<.01 ;{ }^{* * *} \mathrm{p}<.001$ 
Table 5

Relationship between Information Search and Tourism Activities

\begin{tabular}{|c|c|c|c|c|c|c|c|c|c|c|c|c|c|c|c|}
\hline \multirow[b]{2}{*}{ Mean \# Activities } & \multicolumn{3}{|c|}{ Sought Dining Info } & \multicolumn{3}{|c|}{ Sought Parks Info } & \multicolumn{3}{|c|}{ Sought Shopping Info } & \multicolumn{3}{|c|}{ Sought Gaming/Nightlife Info } & \multicolumn{3}{|c|}{ Sought Classic Tourism Info } \\
\hline & yes & no & $F(1,413)$ & yes & no & $F(1,413)$ & yes & no & $F(1,413)$ & yes & no & $F(1,413)$ & yes & no & $F(1,413)$ \\
\hline Dining & 2.4 & 1.93 & $5.7^{*}$ & 2.11 & 2 & 0.15 & 2.23 & 1.98 & 1.09 & 2.29 & 1.98 & 1.77 & 2.18 & 1.98 & 0.95 \\
\hline Parks & 0.93 & 0.6 & $6.32^{*}$ & 1.79 & 0.55 & $59.26^{\star * *}$ & 1.02 & 0.61 & $7.01^{* *}$ & 0.86 & 0.63 & 2.13 & 1.36 & 0.52 & $41.69^{* * *}$ \\
\hline $\begin{array}{l}\text { Shopping } \\
\text { Nightlife \& }\end{array}$ & 1.51 & 1.01 & $11.02^{* *}$ & 1.82 & 1.02 & $16.41^{* * *}$ & 2.06 & 0.97 & $40.52^{* * *}$ & 1.45 & 1.05 & $5.12^{*}$ & 1.64 & 0.99 & $18.1^{* * *}$ \\
\hline $\begin{array}{l}\text { Gaming } \\
\text { Classic }\end{array}$ & 1.72 & 0.93 & $16.29^{* * *}$ & 2.03 & 0.97 & $16.76^{* * *}$ & 1.73 & 0.98 & $10.22^{* *}$ & 2.31 & 0.9 & $39.02^{\star * *}$ & 1.75 & 0.93 & $16.05^{\star * *}$ \\
\hline Tourism & 1.44 & 0.73 & $8.47^{\star *}$ & 2.32 & 0.7 & $25.85^{\star * *}$ & 1.54 & 0.76 & $7.13^{* *}$ & 1.2 & 0.8 & 1.88 & 2.15 & 0.6 & $40.03^{\star * *}$ \\
\hline
\end{tabular}

${ }^{*} p<.05 ;{ }^{* *} p<.01 ;{ }^{* * *} p<.001$ 
Table 6

Final Logistic Regression Analyses for Variables Predicting Specific Information Search

\section{Dining}

\begin{tabular}{lcc}
\hline Variable & B & Wald \\
\hline Previously Visited & -0.67 & $5.57^{*}$ \\
Learning about Destination & 0.36 & $15.29^{\star * *}$ \\
\hline $82.7 \%$ correct classification & & \\
Nagelkerke $R^{2}=.104$ & &
\end{tabular}

Parks \& Gardens

\begin{tabular}{lcc}
\hline Variable & B & Wald \\
\hline Learning about Destination & 0.39 & $11.09^{* *}$ \\
\hline
\end{tabular}

90.8\% correct classification

Nagelkerke $R^{2}=.061$

\section{Nightlife \& Gaming}

\begin{tabular}{lcc}
\hline Variable & $\mathrm{B}$ & Wald \\
\hline Learning about Athletics & -0.30 & $4.01^{*}$ \\
Learning about Destination & 0.40 & $9.75^{\star *}$ \\
\hline
\end{tabular}

$88.2 \%$ correct classification

Nagelkerke $R^{2}=.049$

\section{Shopping}

\begin{tabular}{lcr}
\hline Variable & B & Wald \\
\hline Previously Visited & -1.09 & $8.8^{\star *}$ \\
Learning about Destination & 0.44 & $14.87^{\star * *}$ \\
\hline $89 \%$ correct classification & & \\
Nagelkerke $R^{2}=.145$ & &
\end{tabular}

Classic Tourism Activities

\begin{tabular}{lcc}
\hline Variable & B & Wald \\
\hline Learning about Destination & 0.34 & $14.1^{* * *}$ \\
\hline $84 \%$ correct classification & & \\
Nagelkerke $R^{2}=.059$ & &
\end{tabular}

$\mathrm{df}=1 ;{ }^{*} p<.05 ;{ }^{* *} p<.01 ;{ }^{* * *} p<.001$ 
Table 7

Final Model from Hierarchical Regression Analyses Predicting of Intensity of Specific Tourism Activities

Dining

\begin{tabular}{lccc}
\hline Variables & $\mathrm{B}$ & $\mathrm{SE} \mathrm{B}$ & $\beta$ \\
\hline (Constant) & 1.21 & 0.06 & \\
Info on Dining & 0.18 & 0.07 & $0.12^{*}$ \\
Athlete & -0.56 & 0.07 & $-0.41^{* *}$ \\
Non-athlete Participant & -0.46 & 0.08 & $-0.3^{* * *}$ \\
Previously Visited & -0.15 & 0.06 & $-0.12^{*}$ \\
\hline $\mathrm{R}^{2}$
\end{tabular}

Shopping

\begin{tabular}{lccc}
\hline Variables & B & SE B & $\beta$ \\
\hline (Constant) & 0.64 & 0.04 & \\
Info on Shopping & 0.41 & 0.08 & $0.25^{\star * *}$ \\
Previously Visited & -0.19 & 0.05 & $-0.17^{\star * *}$ \\
\hline $\mathrm{R}^{2}=.106$ & & &
\end{tabular}

\section{Classic Tourism}

\begin{tabular}{lccc}
\hline Variables & $\mathrm{B}$ & $\mathrm{SE} \mathrm{B}$ & $\beta$ \\
\hline (Constant) & 0.28 & 0.08 & \\
Info Classic Tourism & 0.64 & 0.07 & $0.39^{* * *}$ \\
Learn Destination & 0.04 & 0.02 & $0.1^{*}$ \\
Athlete & -0.21 & 0.07 & $-0.15^{*}$ \\
Previously Visited & -0.16 & 0.06 & $-0.13^{* *}$ \\
\hline $\mathrm{R}^{2}=.206$ & & &
\end{tabular}

\section{Parks}

\begin{tabular}{lccc}
\hline Variables & B & SE B & $\beta$ \\
\hline (Constant) & 0.47 & 0.04 & \\
Info on Parks & 0.59 & 0.08 & $0.34^{\star * *}$ \\
Athlete & -0.21 & 0.06 & $-0.18^{\star * *}$ \\
Previously Visited & -0.20 & 0.05 & $-0.21^{* * *}$ \\
\hline$R^{2}=$
\end{tabular}

Nightlife \& Gaming

\begin{tabular}{lccc}
\hline Variables & $\mathrm{B}$ & $\mathrm{SE} B$ & $\beta$ \\
\hline (Constant) & 0.46 & 0.03 & \\
Info Nightlife \& Gaming & 0.53 & 0.09 & $0.28^{* * *}$ \\
\hline $\mathrm{R}^{2}=.079$
\end{tabular}

${ }^{* * *} p<.001 ;{ }^{* *} p<.01 ;{ }^{*} p<.05$ 
Table 8

Final Models for Hierarchical Regression Analyses Predicting Repeat Visitation and Recommendation

Return to destination

\begin{tabular}{lccc}
\hline Variables & B & SE B & $\beta$ \\
\hline (Constant) & 2.28 & 0.20 & \\
Park Activities & -0.32 & 0.17 & -0.09 \\
Class. Tour. Activities & 0.43 & 0.14 & $0.15^{\star *}$ \\
Previously Visited & 1.85 & 0.15 & $0.52^{* * *}$ \\
Escape & 0.16 & 0.05 & $0.13^{* *}$ \\
& & &
\end{tabular}

$\mathrm{R}^{2}=.326$

${ }^{* * *} p<.001 ;{ }^{* *} p<.01 ;{ }^{*} p<.05$
Recommend Destination

\begin{tabular}{lccc}
\hline Variables & B & SE B & $\beta$ \\
\hline (Constant) & 2.24 & 0.22 & \\
Park Activities & -0.33 & 0.17 & $-0.1^{*}$ \\
Class. Tour. Activities & 0.52 & 0.14 & $0.2^{* * *}$ \\
Previously Visited & 0.74 & 0.16 & $0.23^{* \star *}$ \\
Escape & 0.17 & 0.06 & $0.16^{* *}$ \\
Learn. Destination & 0.28 & 0.05 & $0.26^{* \star *}$ \\
\hline
\end{tabular}

${ }^{* * *} p<.001 ;{ }^{* *} p<.01 ;{ }^{*} p<.05$ 
Figure 1: Conceptual Model

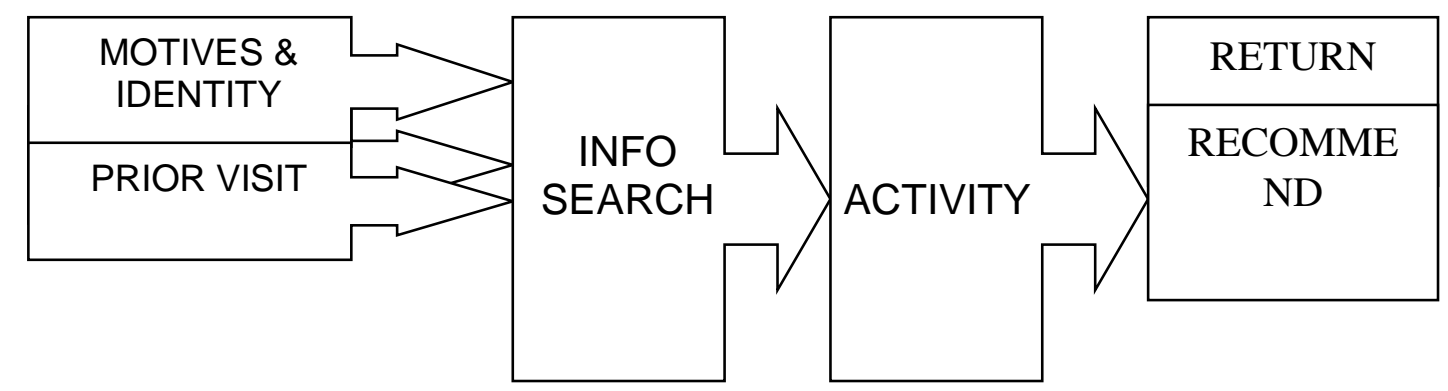


Figure 2: Structure of tourism activities (from smallest space analysis)

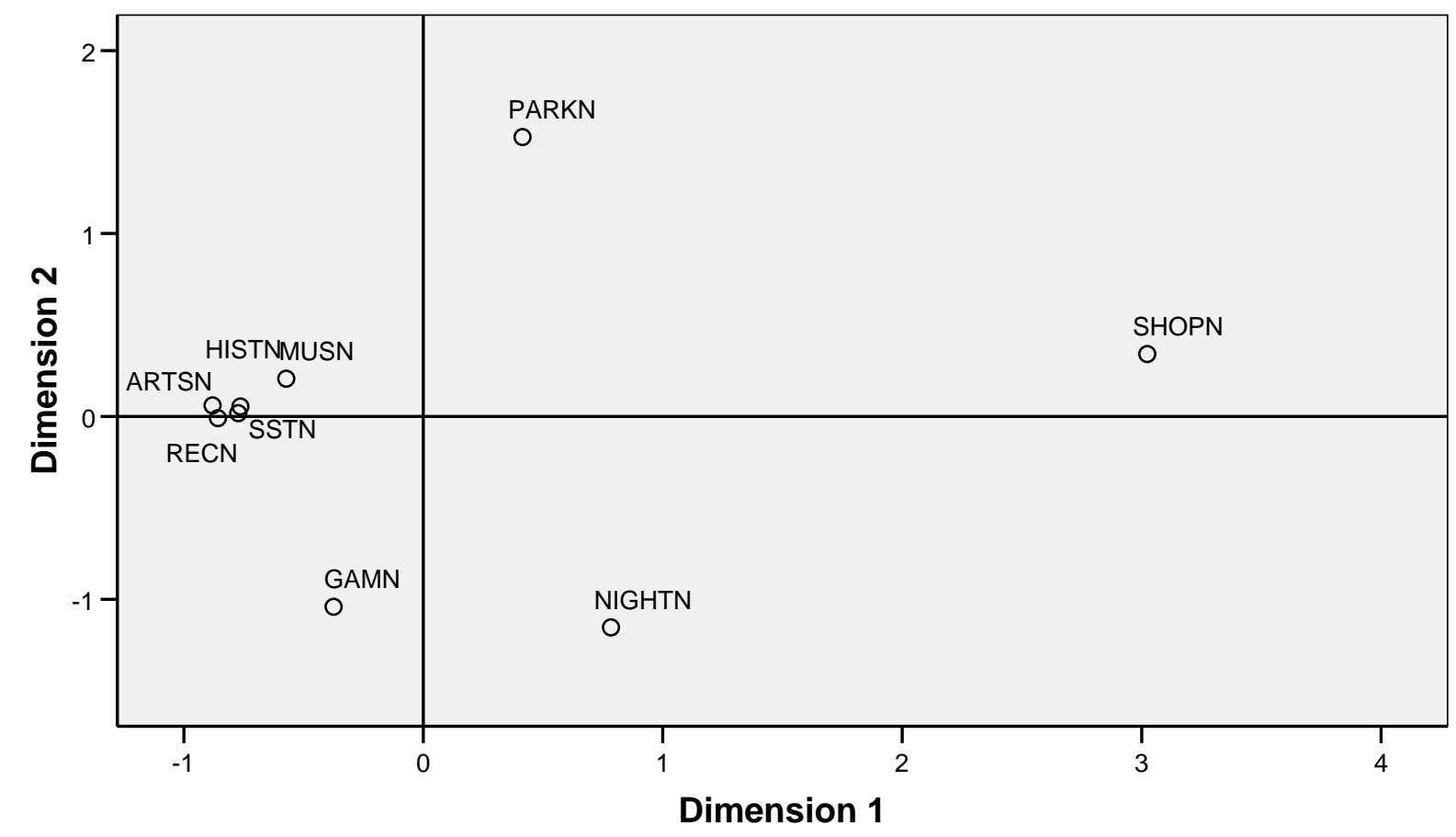




\section{Figure 3: Final Model}

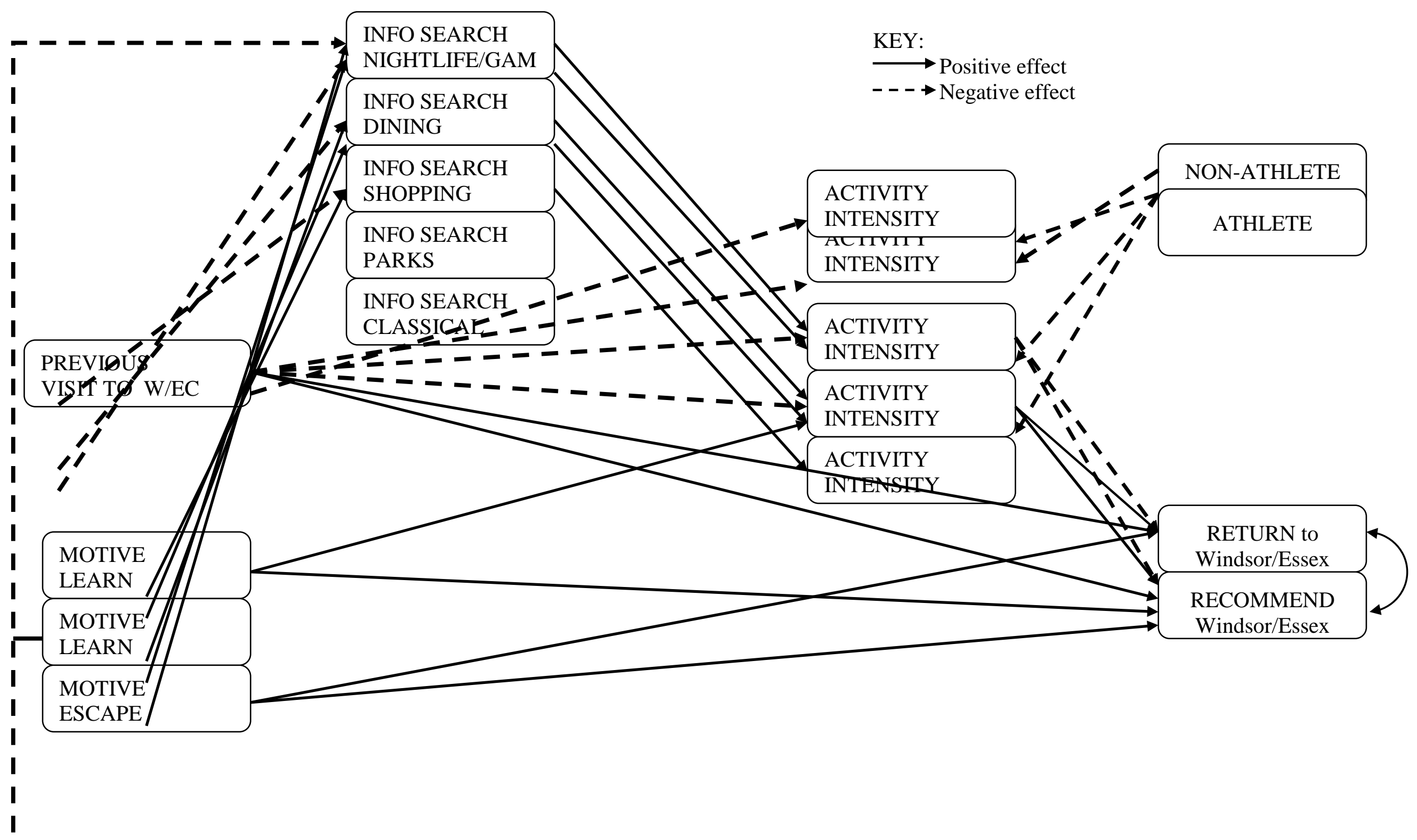

